Article

\title{
Janthinobacterium CG23_2: Comparative Genome Analysis Reveals Enhanced Environmental Sensing and Transcriptional Regulation for Adaptation to Life in an Antarctic Supraglacial Stream
}

\author{
Markus Dieser ${ }^{1,2, *}$, Heidi J. Smith ${ }^{1,3}$, Thiruvarangan Ramaraj ${ }^{4}\left(\mathbb{D}\right.$ and Christine M. Foreman ${ }^{1,2}$ \\ 1 Center for Biofilm Engineering, Montana State University, Bozeman, MT 59717, USA; \\ hjsmith12@gmail.com (H.J.S.); cforeman@montana.edu (C.M.F.) \\ 2 Department of Chemical \& Biological Engineering, Montana State University, Bozeman, MT 59715, USA \\ 3 Department of Microbiology \& Immunology, Montana State University, Bozeman, MT 59717, USA \\ 4 School of Computing, College of Computing \& Digital Media, DePaul University, Chicago, IL 60604, USA; \\ tramaraj@depaul.edu \\ * Correspondence: markus.dieser@montana.edu
}

Received: 25 September 2019; Accepted: 14 October 2019; Published: 15 October 2019

check for updates

\begin{abstract}
As many bacteria detected in Antarctic environments are neither true psychrophiles nor endemic species, their proliferation in spite of environmental extremes gives rise to genome adaptations. Janthinobacterium sp. CG23_2 is a bacterial isolate from the Cotton Glacier stream, Antarctica. To understand how Janthinobacterium sp. CG23_2 has adapted to its environment, we investigated its genomic traits in comparison to genomes of 35 published Janthinobacterium species. While we hypothesized that genome shrinkage and specialization to narrow ecological niches would be energetically favorable for dwelling in an ephemeral Antarctic stream, the genome of Janthinobacterium sp. CG23_2 was on average $1.7 \pm 0.6 \mathrm{Mb}$ larger and predicted $1411 \pm 499$ more coding sequences compared to the other Janthinobacterium spp. Putatively identified horizontal gene transfer events contributed $0.92 \mathrm{Mb}$ to the genome size expansion of Janthinobacterium sp. CG23_2. Genes with high copy numbers in the species-specific accessory genome of Janthinobacterium sp. CG23_2 were associated with environmental sensing, locomotion, response and transcriptional regulation, stress response, and mobile elements-functional categories which also showed molecular adaptation to cold. Our data suggest that genome plasticity and the abundant complementary genes for sensing and responding to the extracellular environment supported the adaptation of Janthinobacterium sp. CG23_2 to this extreme environment.
\end{abstract}

Keywords: Janthinobacterium; comparative genomics; horizontal gene transfer; cold adaptation; environmental sensing

\section{Introduction}

Environments with temperatures permanently below $5{ }^{\circ} \mathrm{C}$ dominate the Earth's biosphere $(>80 \%)$. While much of the cold biosphere is made up of the world's oceans, a combined $37 \%$ of the land area consists of permafrost regions, 198,000 glaciers, and two ice sheets [1-3]. Adaptation to cold temperatures and associated stresses (i.e., desiccation, water activity, radiation, $\mathrm{pH}$, ionic strength, and nutrient availability) [4] allows psychrophilic/psychrotolerant microorganisms to inhabit and even thrive in these extreme and often inhospitable environments. Integrating 'omics' technologies with physiological studies on cold adaptation has advanced our understanding of functional and evolutionary biological processes at the molecular level [5-8]. Specifically, genome comparisons are a 
powerful tool that enables the exploration of molecular level adaptations in microorganisms inhabiting a broad temperature spectrum. Comparative approaches have identified two overarching trends across bacterial genomes. First, genome size appears to correlate with environmental niches and lifestyle, and second, diversification is explained by horizontal gene transfer [9]. Paradoxically, in genomes from cold-adapted bacterial species both diversification $[10,11]$ and streamlining are observed $[6,12]$, resulting in an increased and decreased genome size, respectively.

In the present study, we investigated the genomic properties of Janthinobacterium sp. CG23_2 [13], a bacterium isolated from a supraglacial stream on the Cotton Glacier, Antarctica. Janthinobacterium spp. are frequently isolated from alpine and polar regions [13-22], while others have been identified as amphibian symbionts [23] or pathogens [24]. The genus Janthinobacterium (Betaproteobacteria, Oxalobacteraceae) includes Gram-negative, motile, aerobic, chemoorganoheterotrophic bacteria that are often resistant to a wide range of antibiotics and heavy metals $[16,25,26]$. Janthinobacterium spp. commonly produce violacein, a purple, water-insoluble secondary metabolite [27]; however, pigment color can vary $[14,16,17,19]$.

Unlike most supraglacial streams, which form seasonally in the ablation zone by melt water incisions, the Cotton Glacier stream is a perennial feature. Water only flows during summer melt (4-12 weeks), with variations in stream hydrology related to local daily, seasonal, and interannual climate conditions [28]. The stream bed is devoid of significant amounts of sediments but is flanked by large para-fluvial sediment deposits [29]. Due to the dynamic ephemeral nature of the Cotton Glacier stream, its changing velocity, low in-stream nutrient levels, short residence times, temperatures near or below freezing point, daily freeze-thaw cycles in summer, months of deep-freeze in winter, and extreme transparency to solar UV radiation [28,29], microbial inhabitants must be capable of major metabolic and physiological adjustments year-round. We hypothesized that in order to optimize adaptation to this extremely variable environment, free living microorganisms would form long-lasting metabolic interactions to stabilize their close environment. According to the Black Queen Hypothesis [30], such functional dependencies of sharing genomic resources would select smaller genomes, thereby reducing energetically costly requirements associated with the maintenance of genetic material and metabolic activities; these are genomic features which are characteristic for the oligotrophic environment [31]. Yet, the genome of Janthinobacterium sp. CG23_2 was significantly larger than any previously sequenced Janthinobacterium genome [13]. To discern the genetic attributes of Janthinobacterium sp. CG23_2 that contribute to a larger genome and allow proliferation under these extremely harsh and transient conditions within the Cotton Glacier stream, a comparative genomic approach with 35 Janthinobacterium spp. was performed.

\section{Materials and Methods}

\subsection{Comparative Genome and Phylogenetic Analyses}

The genomes of 35 Janthinobacterium species/strains publicly available at the National Center for Biotechnology Information (NCBI) were used for comparison to the Janthinobacterium CG23_2 genome (Table 1). Due to the low percentage match to the other Janthinobacterium spp. (Table S1), genomes from Janthinobacterium spp. B9-8, Marseille, HH01, CG3, and NBRC.102515 were excluded from core gene analysis. Core genes were identified using the algorithm described in Cleary et al. [32], which constructs a compressed de Bruijn graph (CDBG) of a genome population and identifies core genes using the frequently visited regions in the graph. Subsequently, the coding sequences (CDSs) of the Janthinobacterium CG23_2 genome were mapped to the core genes using GMAP v1.8 [33]. Default settings were applied except for the "maximum number of paths to show" flag, which was set to 1. The GMAP alignment was filtered for $\geq 90 \%$ query coverage and $\geq 80 \%$ identity. The same parameters were selected in the GMAP v1.8 software package for pairwise comparisons of CDSs identified in the 36 Janthinobacterium spp. genomes. 
Table 1. Summary of the 36 Janthinobacterium genome statistics. (HA: host-associated).

\begin{tabular}{|c|c|c|c|c|c|c|c|c|c|}
\hline Genome Name & Isolation Source & Size $(\mathbf{M b})$ & \# Contigs & N50 (Mb) & Total \# Genes & $\begin{array}{l}\text { \# Protein Coding } \\
\text { Sequences }\end{array}$ & $\begin{array}{l}\# 16 S \\
\text { rRNA }\end{array}$ & GC\% & $\begin{array}{l}\text { NCBI ID } \\
\text { (GCA_) }\end{array}$ \\
\hline Janthinobacterium sp. CG23_2 & polar, glacial & 7.85 & 4 & 4.20 & 6974 & 6859 & 7 & 63.5 & 001485665.1 \\
\hline J. sp. HH01 & aquatic, sediments & 7.11 & 2 & 4.21 & 6172 & 6063 & 7 & 64.2 & 000335815.1 \\
\hline J. sp. RA13 & aquatic, sediments & 6.42 & 1 & 6.42 & 5740 & 5619 & 8 & 62.5 & 000745325.1 \\
\hline J. sp. HH100 & aquatic, sediments & 6.70 & 150 & 0.09 & 6044 & 5987 & 1 & 62.6 & 001758685.1 \\
\hline J. sp. HH102 & aquatic, sediments & 6.65 & 125 & 0.31 & 6010 & 5961 & 10 & 62.4 & 001758625.1 \\
\hline J. sp. HH103 & aquatic, sediments & 6.58 & 141 & 0.10 & 5964 & 5901 & 1 & 62.5 & 001758705.1 \\
\hline J. sp. HH104 & aquatic, sediments & 6.39 & 65 & 0.23 & 5701 & 5643 & 1 & 62.6 & 001758715.1 \\
\hline J.sp. HH106 & aquatic, sediments & 6.31 & 73 & 0.19 & 5651 & 5595 & 1 & 62.9 & 001758725.1 \\
\hline J.sp. HH107 & aquatic, sediments & 6.16 & 116 & 0.11 & 5517 & 5459 & 1 & 63.1 & 001758765.1 \\
\hline J. psychrotolerans sp. S3-2 & aquatic, sediments & 5.84 & 62 & 0.26 & 5265 & 5174 & 8 & 63.0 & 001677885.1 \\
\hline J.sp. GW456P & aquatic, sediments & 6.27 & 92 & 0.13 & 5633 & 5553 & 7 & 62.9 & 002127655.1 \\
\hline J. sp. GW456W & aquatic, sediments & 6.26 & 149 & 0.08 & 5660 & 5579 & 7 & 62.9 & 002127615.1 \\
\hline J. sp. GW458P & aquatic, sediments & 6.28 & 157 & 0.08 & 6584 & 5611 & 4 & 63.3 & 002127585.1 \\
\hline J.sp. GW460P & aquatic, sediments & 6.27 & 120 & 0.09 & 5650 & 5566 & 8 & 62.9 & 002127625.1 \\
\hline J.sp. GW460W & aquatic, sediments & 6.27 & 104 & 0.11 & 5637 & 5555 & 7 & 62.9 & 002127575.1 \\
\hline J.sp. LM6 & aquatic, sediments & 6.29 & 1 & 6.29 & 5523 & 5401 & 8 & 63.0 & 002002885.1 \\
\hline J. agaricidamnosum NBRC 102515 & HA: mushroom & 5.95 & 1 & 5.95 & 5204 & 5119 & 1 & 61.1 & 000723165.1 \\
\hline J. lividum RIT308 & HA: plant & 6.21 & 44 & 0.30 & 5554 & 5464 & 4 & 62.8 & 000632025.1 \\
\hline J. lividum MTR & HA: amphibian & 6.54 & 144 & 0.15 & 5874 & 5804 & 3 & 62.4 & 000783415.1 \\
\hline J.sp. MP5059B & HA: fungus & 6.46 & 25 & 0.38 & 5775 & 5681 & 6 & 62.7 & 001758645.1 \\
\hline J. sp. OK676 & HA: plant & 6.27 & 35 & 0.35 & 5589 & 5502 & 2 & 62.8 & 900103595.1 \\
\hline J. sp. YR213 & HA: root & 6.42 & 16 & 0.84 & 5753 & 5625 & 6 & 62.7 & 900099875.1 \\
\hline J. sp. TND4EL3 & HA: plant & 6.52 & 78 & 0.28 & 5915 & 5833 & 6 & 62.9 & 900156175.1 \\
\hline J. lividum NFR18 & HA: root & 6.30 & 26 & 0.50 & 5592 & 5510 & 2 & 62.5 & 900119665.1 \\
\hline J. sp. Ant5-2-1 & polar, glacial & 6.20 & 1703 & 0.003 & 5597 & 5532 & 8 & 62.5 & 001445815.1 \\
\hline J.sp. CG3 & polar, glacial & 6.27 & 41 & 0.78 & 5460 & 5365 & 3 & 65.5 & 000344615.1 \\
\hline J. lividum PAMC 25724 & polar, glacial & 4.98 & 48 & 0.25 & 4428 & 4335 & 9 & 60.6 & 000242815.2 \\
\hline J. lividum ERGS5:01 & polar, glacial & 5.17 & 16 & 3.37 & 4715 & 4596 & 8 & 60.5 & 001678745.2 \\
\hline J. sp. KBS0711 & soil & 6.07 & 149 & 0.09 & 5438 & 5362 & 1 & 62.7 & 000988085.1 \\
\hline J. lividum $\mathrm{H}-24$ & soil & 6.71 & 125 & 0.12 & 5916 & 5874 & 4 & 62.4 & 001758635.1 \\
\hline J. sp. 344 & soil & 6.44 & 35 & 0.43 & 5612 & 5526 & 2 & 63.7 & 900112025.1 \\
\hline J. sp. 551a & soil & 6.46 & 38 & 0.51 & 5626 & 5541 & 1 & 63.6 & 900103675.1 \\
\hline J. lividum MEG1 & soil & 6.60 & 16 & 1.11 & 5893 & 5810 & 1 & 62.3 & 001854915.1 \\
\hline J. sp. 1_2014MBL_MicDiv & soil & 6.45 & 1 & 6.45 & 5648 & 5525 & 8 & 63.6 & 001865675.1 \\
\hline J. sp. Marseille & Engineered systems & 4.11 & 1 & 4.11 & 3870 & 3814 & 2 & 54.2 & 000013625.1 \\
\hline J. sp. B9-8 & Engineered systems & 4.73 & 1 & 4.73 & 4295 & 4179 & 10 & 48.7 & 000969645.2 \\
\hline
\end{tabular}


A Janthinobacterium spp. genome tree was inferred using CheckM [34]. CheckM identifies, annotates, concatenates, and aligns 43 marker genes, which were subsequently placed onto a reference genome tree using the implemented pplacer software package [35]. The Maximum Likelihood tree was computed in MEGA7 [36]. The phylogenetic tree was visualized using iTOL version 4.3 [37]. Whole genome sequence in silico DNA-DNA hybridization (DDH) and average nucleotide identity (ANI) between Janthinobacterium sp. CG23_2 and Janthinobacterium spp. (Table 1) were determined using the default settings for the genome-to-genome distance calculator GGDC 2.1 in combination with the BLAST+ alignment tool [38] and the Average Nucleotide Identity calculator [39,40], respectively. As recommended by the developers [38], results from Formula 2 were considered for DDH, as these estimates are more robust against the use of incomplete draft genomes.

\subsection{Molecular Analysis of Cold Adaptation}

Cold adaptation of proteins from Janthinobacterium sp. CG23_2 was identified using a publicly available python script [6]. Two custom databases were generated, using Janthinobacterium spp. isolated from mesophilic (31 annotated genomes) and polar/glacial environments (four annotated genomes) (Table 1). The annotated genome from Janthinobacterium sp. CG23_2 was compared to these databases using BLASTP [41] with a cutoff score $E$-value $\leq 10^{-15}$. Cold-adaptation scores were assigned to each protein based on the following parameters: arginine to lysine ratio; frequency of acidic residues; proline residues; aromaticity; aliphacity; and grand average of hydropathicity (GRAVY) [6]. Cold adaptation was inferred for each index if the direction of change was significant for fewer proline and acidic residues, and lower R/K (arginine/lysine) ratios, aliphacity, aromaticity, and GRAVY. Proteins with $\geq 3$ cold-adaptation indices were determined as being cold-adapted. [6]. Clusters of orthologous groups (COGs) were annotated with WebMGA using default settings [42] and mapped identified COGs against the updated COGs database [43].

\subsection{Horizontal Gene Transfer (HGT)}

HGTector [44]; was used to identify putative horizontally transferred genes. All-against-all BLASTP [41] was performed against the NCBI non-redundant protein sequences database with an $E$-value cutoff $\leq 10^{-10}, \geq 30 \%$ identity, and $\geq 70 \%$ sequence coverage. The protein sequence database, taxonomy database, and a protein-to-taxonomy dictionary were downloaded on August 15, 2018 from the NCBI website. Up to 100 non-redundant hits per protein were preserved. Hits to more than one organism under the same species were excluded. Janthinobacterium was defined as the self group (NCBI taxonomic ID: 29580), and Burkholderiales as the close group (NCBI taxonomic ID: 1224). The distal group was comprised of all other organisms. Cutoffs of 7.04, 5.55, and 0.79 for the self, close, and distal group, respectively, were computed using the kernel density estimation function. The cutoff in the self weight distribution was included to predict putatively HGT-derived genes that were acquired by specific organisms within the self group. COGs of predicted HGT-derived genes were annotated with WebMGA using default settings [42] and mapped identified COGs against the updated COGs database [43]. Due to their phylogenetic distance and lack of gene similarity between the other Janthinobacterium spp. (0.0-3.8\%; Table S1), Janthinobacterium spp. Marseille and B9-8 were excluded from this analysis.

\section{Results}

\subsection{Genome Statistics of Janthinobacterium spp.}

Genome statistics for all 36 Janthinobacterium spp. are summarized in Table 1. Genome sizes (4.11-7.85 Mb) and number of CDSs (3870-6859) varied across the analyzed species/strains. All species/strains had a high mole percent GC content (60.5-65.5\%), except for Janthinobacterium spp. Marseille (54.25) and B9-8 (48.7). Janthinobacterium sp. CG23_2 had the largest genome with $7.85 \mathrm{Mb}$. Its genome was on average $1.7 \pm 0.6 \mathrm{Mb}$ larger and predicted $1411 \pm 499$ more CDSs compared to the other Janthinobacterium spp. (Table 1). Calculated DDH and ANI values for Janthinobacterium 
sp. CG23_2 were $21.5 \pm 1.8 \%$ and $79.3 \pm 0.4 \%$ (Table S2), respectively, and thus below the threshold boundaries (DDH: 70\% and ANI: 95\%) for members of the same species. Phylogenetic reconstruction of the 36 Janthinobacterium spp. using 43 marker genes identified by CheckM placed Janthinobacterium sp. CG23_2 near the root of the tree (Figure 1). Janthinobacterium spp. isolated in close proximities (i.e., Janthinobacterium spp. CG23_2/CG3; 551a/334; GW spp.; and HH100- spp.) were more closely related. Janthinobacterium spp. Marseille and B9-8, the two species with the smallest genome sizes and considerably lower GC contents, were most distantly related to all other members of the genus Janthinobacterium investigated (Figure 1 and Figure S1).

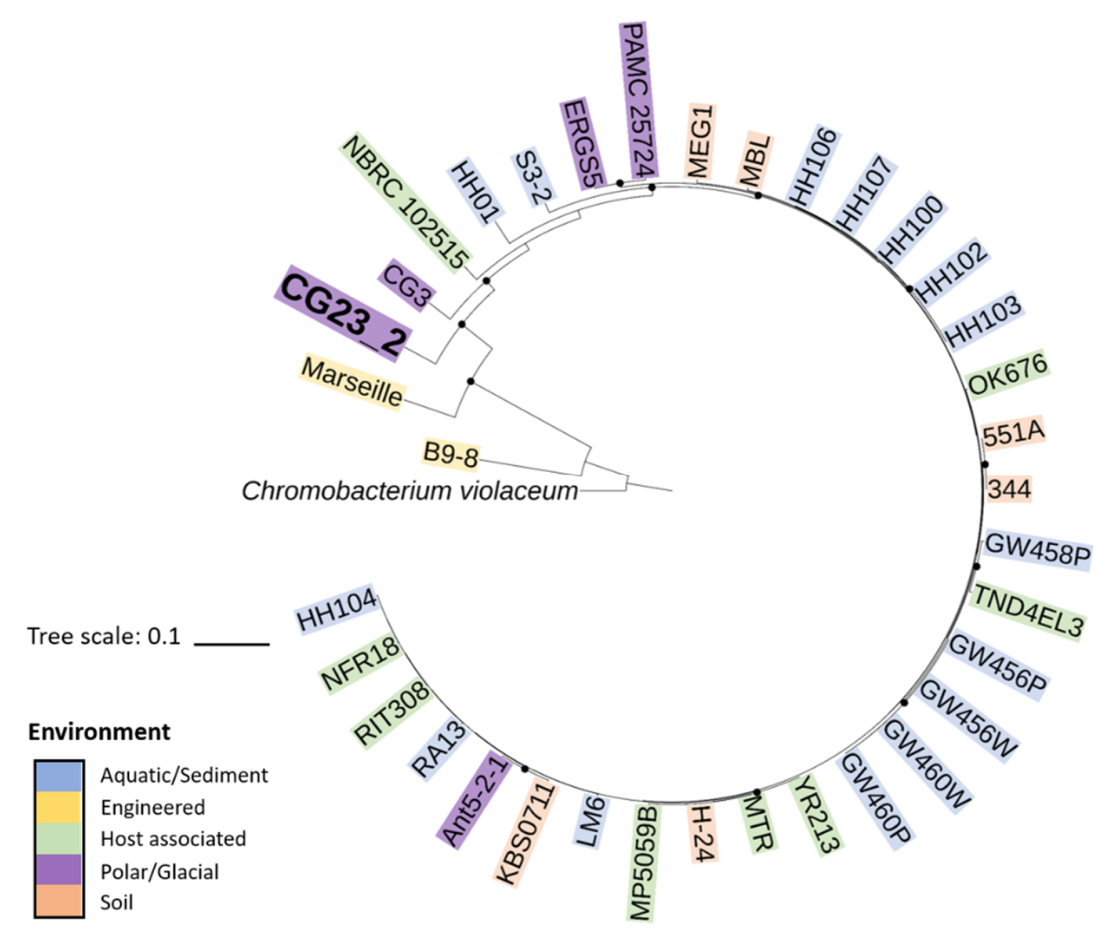

Figure 1. Maximum Likelihood tree of 36 Janthinobacterium spp. based on the Whelan And Goldman (WAG) +Freq. model. The tree is rooted to Chromobacterium violaceum (i.e., bacterium from closely related genera). The tree with the highest log likelihood $(-37179.26)$ is shown. Circles indicate bootstrap values $\geq 0.9$.

Collectively, Janthinobacterium sp. CG23_2 had only 1282 CDSs (18.7\%) in common with the other 35 Janthinobacterium spp., as determined by pairwise comparison. Overlap between Janthinobacterium sp. CG23_2 and each of the 35 Janthinobacterium spp. genomes was low and ranged between $7.2 \%$ and 12.1\% (Figure 2). Likewise, Janthinobacterium spp. B9-8, Marseille, HH01, CG3, and NBRC.102515 had little genome overlap with the other Janthinobacterium spp. (0-25\% on average; Table S1). These six Janthinobacterium spp. with low percentage match $(<25 \%)$ to the other Janthinobacterium spp. were excluded for core gene analysis. For the remaining 30 Janthinobacterium spp. 3260 core CDSs were identified. Only 164 CDSs were shared between Janthinobacterium sp. CG23_2 and the core genes, indicating the prevalence of the Janthinobacterium sp. CG23_2 species-specific accessory genome. Core genes were 12- and 4-fold enriched in the COG categories J and C, respectively, relative to those found specific to Janthinobacterium sp. CG23_2 (Figure 3). Conversely, the species-specific accessory genome of Janthinobacterium sp. CG23_2 was 13 -fold enriched in COG category T, and 4-5 fold in categories V, M, G, and Q, relative to those identified as core genes (Figure 3). COG categories N, W, and $\mathrm{X}$ were only identified in the species-specific accessory genome of Janthinobacterium sp. CG23_2. 


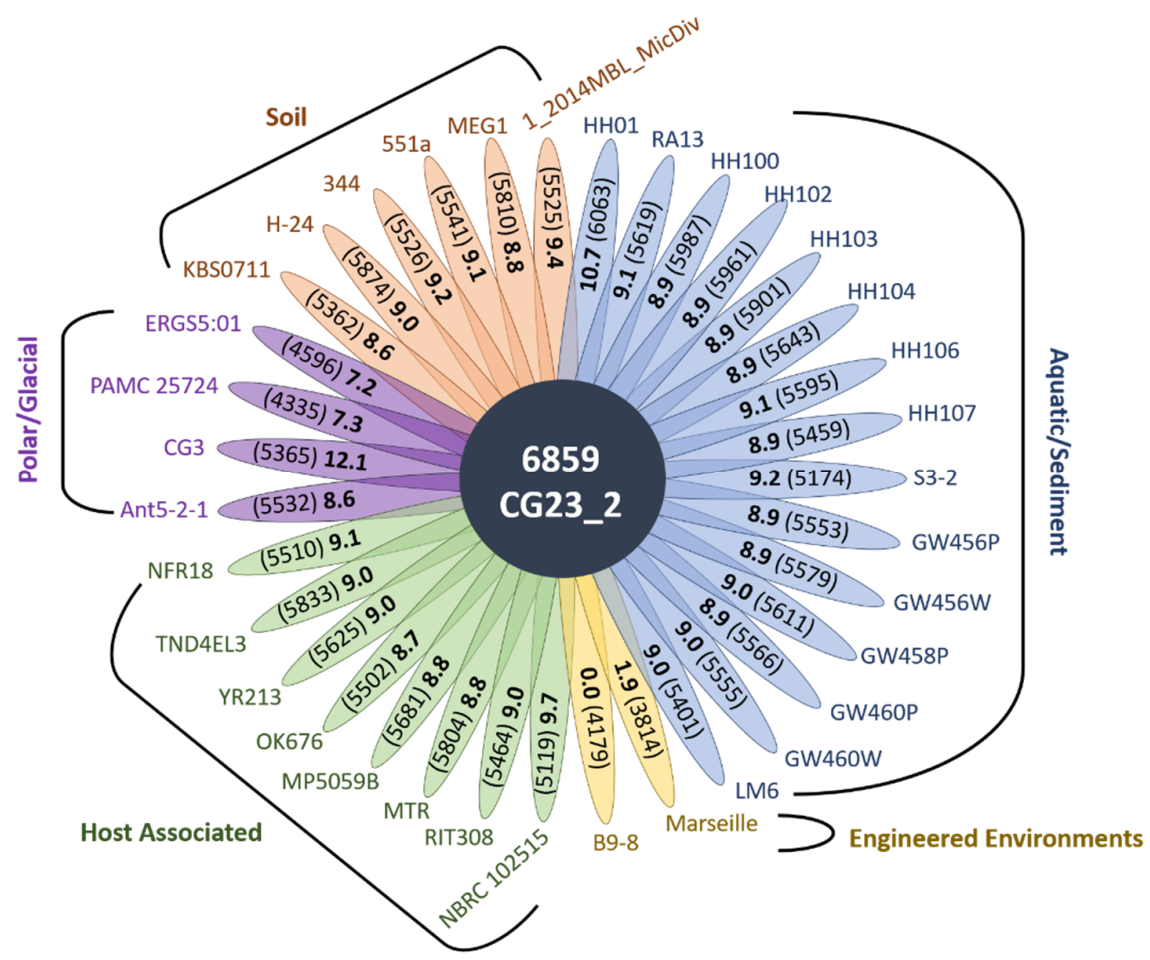

Figure 2. Pairwise gene comparison between Janthinobacterium sp. CG23_2 and the 35 Janthinobacterium spp. with a $90 \%$ query coverage and an $80 \%$ identity. The total number of genes from CG23_2 is in the figure center. Each petal depicts the percentage of shared genes (bold) and the total number of predicted protein coding sequences (in parentheses) for each strain.

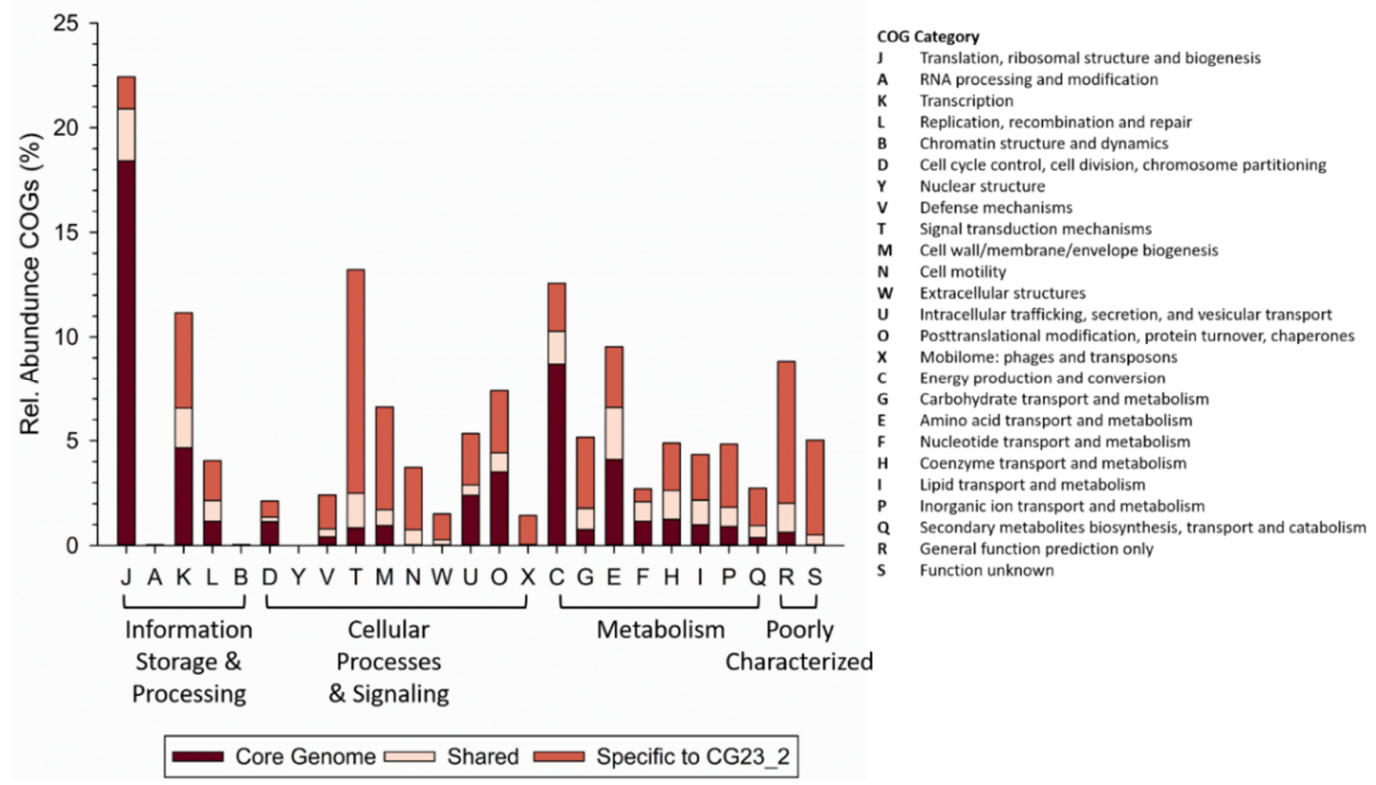

Figure 3. Relative abundance of functional classification of annotated protein coding genes normalized to the total number of protein coding genes for the core genome, shared between Janthinobacterium sp. CG23_2 and $n \geq 2$ species/strains, and species-specific to Janthinobacterium sp. CG23_2. Protein coding genes lacking specific functional assignments were excluded. COGs: clusters of orthologous groups.

The species-specific accessory genome of Janthinobacterium sp. CG23_2 contained 81\% of the total number of CDS, which equates to 5144 proteins sequences, clustering into 3793 orthologs. COGs with copy numbers $n \geq 10$ are summarized in Figure 4 . The highest percentage of the genes in these COG categories were associated with signal transduction histidine kinases $(n=123)$. 
Likewise, c-di-GMP synthetases $(n=46)$, c-di-GMP phosphodiesterases $(n=28)$, CheY-like receivers $(n=43)$, and response regulators containing a CheY-like receiver domain $(n=84)$ were prevalent. Further, prominent COGs of the species-specific accessory genome were transcriptional regulators $(n=115)$ and transposases $(n=27)$. Numerous copies of short-chain alcohol dehydrogenases $(n=21)$ and glutathione S-transferases $(n=15)$ were identified. Intercellular competition was mediated by Rhs family proteins ( $n=35$; COG3209). Motility was supported by methyl-accepting chemotaxis protein $(n=29)$, different chemotaxis proteins/regulators/signal transduction proteins $(n=19)$, and a variety of proteins involved in the assembly and function of pili and flagella $(n=112)$. A total of 42 COGs, including lysozymes $(n=6)$, integrases $(n=4)$, terminases $(n=3)$, and genes encoding phage components $(n=13)$ were related to phage proteins.

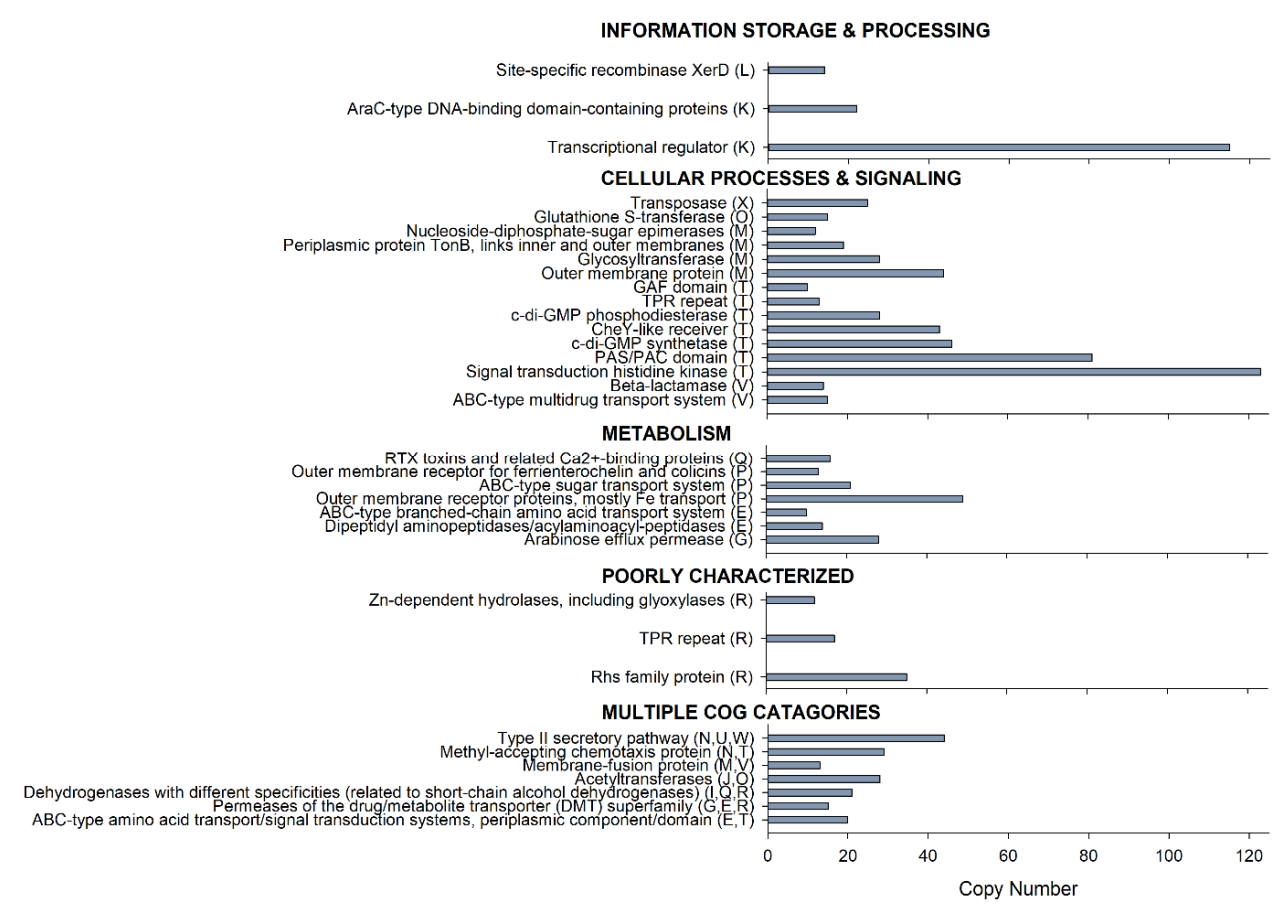

Figure 4. Janthinobacterium sp. CG23_2 species-specific clusters of orthologous groups (COGs). Only COGs with $n \geq 10$ copy numbers are shown.

\subsection{Genome-Wide Molecular Cold-Adaptation of Janthinobacterium sp. CG23_2}

Cold-adaptation of the entire Janthinobacterium sp. CG23_2 genome was inferred from substitution patterns across amino acids using the protein coding sequences of the other 35 Janthinobacterium spp. as comparative databases. Across the Janthinobacterium sp. CG23_2 genome, 27\% $(n=1760)$ and 9\% $(n=577)$ of the protein coding sequences indicated cold adaptation when compared to the mesophilic (i.e., 31 Janthinobacterium spp.) and polar/glacial (i.e., four Janthinobacterium spp.) database, respectively. Noteworthy differences were found in the number of protein coding sequences that were classified as neutral between Janthinobacterium sp. CG23_2 and the two databases. The number of protein coding sequences with no significant changes in the amino acid content for Janthinobacterium sp. CG23_2 and Janthinobacterium spp. isolated from other polar/glacial environments was 2.3 times $(n=1687)$ higher compared to the database built from Janthinobacterium spp. isolated from mesophilic environments. Overall, Janthinobacterium sp. CG23_2 had significantly more proteins that possessed lower aliphacity, $\mathrm{R} / \mathrm{K}$ (arginine/lysine) ratios, and aromaticity when compared to their counterparts from mesophilic environments (Bonferroni-corrected $p \leq 0.001$; Figure 5A-C). Conversely, the GRAVY index was found to be significantly enriched (Bonferroni-corrected $p=0.001$; Figure 5A-C). When compared to the four Janthinobacterium spp. isolated from polar/glacial environments, the Janthinobacterium sp. CG23_2 
genome was significantly cold-adapted for aliphacity while enriched in proline and acidic residues (Bonferoni corrected $p \leq 0.005$; Figure 5B,C).

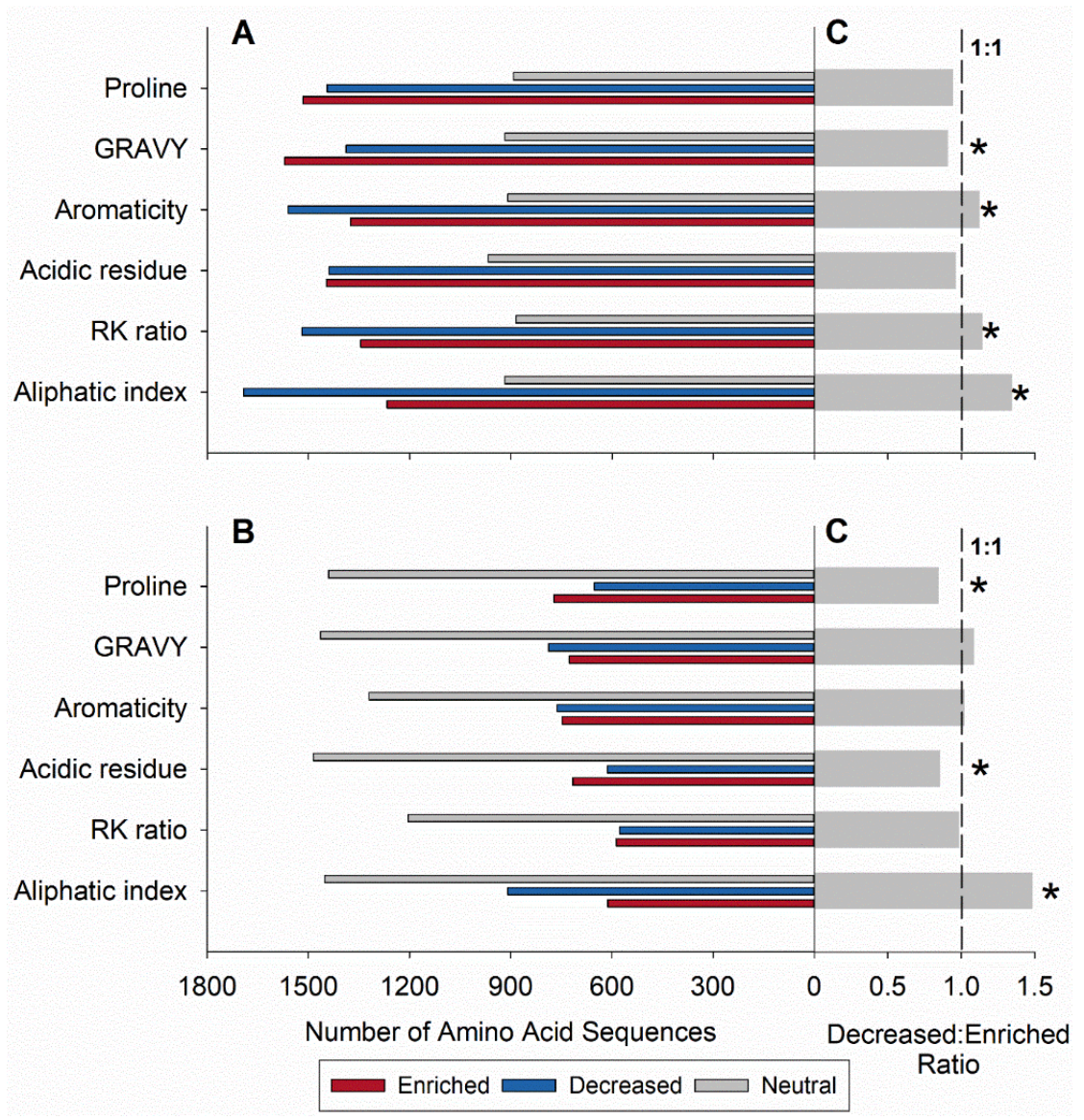

Figure 5. Genome-wide molecular cold-adaptation in CG23_2 compared to (A) 31 Janthinobacterium spp. isolated from mesophilic environments and (B) four Janthinobacterium spp. found in polar/glacial regions. (C) Adaptation ratios (decreased: enriched) with significant indices are indicated with an asterisk (Bonferroni-corrected $p \leq 0.005$ ). Decrease indicates cold adaptation. GRAVY: grand average of hydropathicity; R/K: arginine/lysine.

COGs were identified for $90 \%(n=1583)$ of the cold-adapted protein coding sequences in Janthinobacterium sp. CG23_2. Cold-adapted proteins were associated with key processes including transport, environmental sensing, locomotion, defense and stress response, macromolecular syntheses, degradation, and repair, as well as key enzymes in central pathways and their intermediates (Figure 6; Table S3). COGs in high abundance were ABC transporters (i.e., components of the ATP binding cassette) involved in amino acid ( $n=19$; COG0411, COG0683, COG0834, COG1126, COG0765, COG4177, COG0559), multidrug $(n=13$; COG1131, COG1132), sugar $(n=10$; COG1129, COG1653, COG3839, COG0395, COG1175), and nitrate/sulfonate/bicarbonate $(n=8$; COG0715, COG1116, COG0600) transport. Multiple copies of cold-adapted ABC transporters were found for antimicrobial peptides ( $n=7$; COG0577, COG1136) and organic solvent resistance $(n=3$; COG1127, COG2854, COG0767). Choline dehydrogenases $(n=2$; COG2303) and the corresponding choline-glycine betaine ABC-type transport system (COG1732) were found to be cold-adapted. Thirty-nine cold-adapted proteins were characterized as outer membrane receptor proteins, mainly involved in iron transport $(n=28$; COG1629). Cold-adapted efflux pumps such as arabinose efflux permeases ( $n=17$; COG2814), cation/multidrug efflux pumps ( $n=9$; COG0841), and multidrug resistance efflux pumps ( $n=5$; COG1566) were indicative of proteins engaged in transmembrane transport. Secretion 
of proteins into the extracellular space was represented by 28 copies of Type II secretory proteins (Table S3).

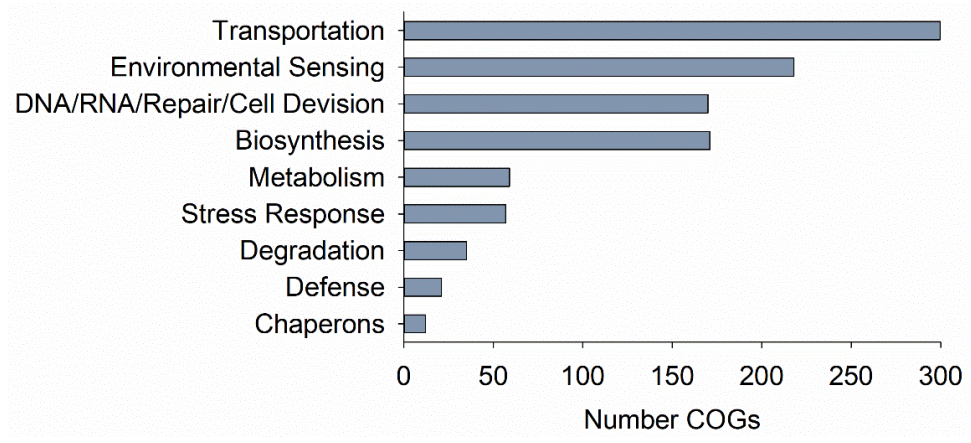

Figure 6. Number of clusters of orthologous groups (COGs) associated with different functions identified for cold-adapted protein sequences in Janthinobacterium sp. CG23_2.

A large number of cold-adapted proteins $(n=238)$ were associated with environmental sensing (Table S3). The genome of Janthinobacterium sp. CG23_2 contained multiple copies of CheY chemotaxis proteins ( $n=5$; COG0784) and a methyl-accepting chemotaxis protein ( $n=16$; COG0840). Major proteins involved in sensing of and adaptation to environmental signals were signal transduction histidine kinases ( $n=48$; COG0642) and c-di-GMP synthetases ( $n=27$; COG2199). Three proteins involved in the biosynthesis of histidine were identified as cold-adapted (imidazoleglycerol-phosphate dehydratase (COG0131), histidinol phosphatase (COG0241), and imidazolonepropionase (COG1228)). Cellular response regulators were predominantly CheY-like receivers $(n=67$; COG3706, COG0745, COG2204, COG3437, COG2197, COG2201). Proteins affecting flagellar activity were associated with the motor ( $n=3$; COG1291, COG1360, COG1536), basal body $(n=14$; COG2063, COG1766, COG1558, COG1706, COG1261, COG1815, COG1580), and hook ( $n=9$; COG1344, COG1749, COG1256, COG1677) of the flagellar complex. Further, cold adaptation included several proteins involved in flagellar biosynthesis (Table S3) and flagellar biosynthesis chaperones (COG2882, COG1516). Proteins related to environmental stress responses were primarily identified for detoxification ( $n=17$; COG0625, COG0491, COG0346) and protection against oxidative stress $(n=20$; COG0753, COG1764, COG1225, COG0494, COG0225, COG1858, COG0386, COG0189, COG0695, COG3118, COG0783). Virulence factors such as RTX toxins ( $n=2$; COG2931), Rhs family proteins regulating intercellular competition ( $n=5$; COG3209), Type IV protein secretion systems participating in virulence and antibacterial activities $(n=5$; COG3519, COG3157, COG3455, COG3523), and beta-lactamases providing antibiotic resistance $(n=7 ;$ COG1680) were identified as potential defense mechanisms.

Janthinobacterium sp. CG23_2 had 24 and 18 cold-adapted COGs crucial for DNA replication and repair, respectively (Table S3). Overall, 113 proteins denoting 27 COGs were associated with transcriptional functions, dominated by transcriptional regulators ( $n=72$; COG1309, COG1522, COG4977, COG3829, COG1167, COG2909, COG4650). Multiple copies of proteins responsible for methylation (a mechanism protecting newly synthesized DNA from endonucleases) were identified for the methylase of chemotaxis methyl-accepting proteins $(n=3$; COG1352) and polypeptide chain release factors $(n=2$; COG2890).

Several proteins involved in key metabolic steps of the citric acid cycle (TCA) were cold-adapted. These included pyruvate dehydrogenase (COG2609), citrate synthase (COG0372), isocitrate dehydrogenase (COG0473, COG0538), 2-oxoglutarate dehydrogenase (COG0508), and succinate dehydrogenase (COG1053, COG2009). Glucokinase (COG0837), the first step of glycolysis, and multiple copies of short-chain alcohol dehydrogenases ( $n=18$; COG1028, COG4221) and lactate dehydrogenases ( $n=2$; COG1052), both essential during fermentation, were identified. Additionally, proteins supporting carboxydotrophy were cold-adapted (Table S3). Of relevance were proteins efficient in generating precursors or intermediates (e.g., galactose, propionate, glucose, ribulose-5-phosphate, 
fructose-6-phosphate, pyruvate, acytl-CoA, oxaloacetate) (Table S3) that can be used in catabolic and anabolic pathways to generate ATP or synthesize macromolecular subunits.

A subset of 48 cold-adapted proteins (Table S3) were involved in the biosynthesis of membrane constituents and included phosphoglycerides (e.g., glycerol-3-phosphate dehydrogenase $(n=2$; COG0240)), phospholipids (phosphatidylserine synthases $(n=4$; COG1502), peptidoglycan (e.g., glycosyltransferase $(n=6$; COG0438), and D-alanine-D-alanine ligase $(n=3$; COG1181)), fatty acids (e.g., acyl-CoA synthetases ( $n=4$; COG0318) and 3-oxoacyl-(acyl-carrier-protein) synthase $(n=3$; COG0304)), and lipopolysaccharides (e.g., sugar transferases involved in lipopolysaccharide synthesis $(n=3 ;$ COG2148)). Janthinobacterium sp. CG23_2 had cold-adapted phospholipase (COG3240), amidase (COG3023, COG0860), transglycosylase (COG0741), and peptidase (COG2173, COG1686) required for the continuous remodeling of cellular membranes. Thiol-disulfide isomerase ( $n=5$; COG0526) and acetyltransferases ( $n=7$; COG0456, COG1670), which catalyze protein folding and acetylation, respectively, were among the cold-adapted proteins. Three out of the four proteins involved in beta-oxidation were cold-adapted and included multiple copies of acyl-CoA dehydrogenases $(n=8$; COG1960), enoyl-CoA hydratase/carnithine racemases ( $n=3$; COG1024), and 3-hydroxyacyl-CoA dehydrogenases $(n=3$; COG1250).

\subsection{Horizontal Gene Transfer in Janthinobacterium sp. CG23_2}

Putative HGT events across 34 Janthinobacterium spp. (excluding Marseille and B9-8) are summarized in Figure 7. Janthinobacterium sp. CG23_2 had the highest number of horizontally transferred genes, with $11.5 \%$ of its protein coding genes predicted to be the result of HGT events (Figure 7A). Notably, this was $8.8 \pm 1.6 \%$ above the average for the other Janthinobacterium strains. The predicted gain by HGT was $0.92 \mathrm{Mb}$ in Janthinobacterium sp. CG23_2, which was substantially higher than the average of $0.17 \pm 0.11 \mathrm{Mb}$ for the other Janthinobacterium strains (Figure 7A). Janthinobacterium spp. that were isolated from the same site such as H100/H103, GW456P,W/GW460P,W, and 551a/344 showed almost identical HGT events (Figure 7B). Genes linked to HGT in Janthinobacterium sp. CG23_2 were predominately derived from Pseudomonadales (17.1\%), Xanthomonadales $(9.6 \%)$, Neisseriales $(7.3 \%)$, Rhizobiales (5.5\%), and Nitrosomonadales (4.8\%), similar to the other Janthinobacterium species (Figure 7B). Specifically, Pseudomonas spp. $(n=89)$, Rugamonas rubra $(n=28)$, Hyalangium minutum $(n=19)$, and Lysobacter dokdonensis DS-58 $(n=16)$ were dominant predicted gene donors.

Of the 741 putatively identified HGT events in Janthinobacterium sp. CG23_2, 292 or 4.5\% of the whole genome of Janthinobacterium sp. CG23_2 clustered into COGs. COG categories of genes involved in environmental sensing included signal transduction histidine kinases $(n=6$; COG0642), second messengers $(n=5$; COG2199), and response regulators $(n=3$; COG2197) (Table 2). Noticeable were functions associated with defense mechanisms, production of compatible solutes, and the mobilome. These genes comprised Rhs family proteins ( $n=13$; COG3209), RTX toxins and related $\mathrm{Ca}^{2+}$-binding proteins ( $n=7$; COG2931), beta-lactamase and other penicillin binding proteins ( $n=4$, COG1680), choline dehydrogenases $(n=4$; COG2303), phage proteins $(n=18)$, and transposases $(n=6)$ (Table 2$)$. Other abundant HGT-acquired genes included short-chain alcohol dehydrogenases $(n=8$; COG1028, COG4221) and mannose-6-phosphate isomerases $(n=4$; COG0662). HTG was predicted for genes encoding for the biosynthesis of peptidoglycan (glycosyltransferase; $n=5 ;$ COG0438) and fatty acids (3-oxoacyl-(acyl-carrier-protein) synthase; $n=4$; COG0304). Acetyltransferases ( $n=6$; COG0456, COG1670) with relevance to protein modifications and proteins containing pentapeptide repeats $(n=6$; COG1357) were of HGT origin. 

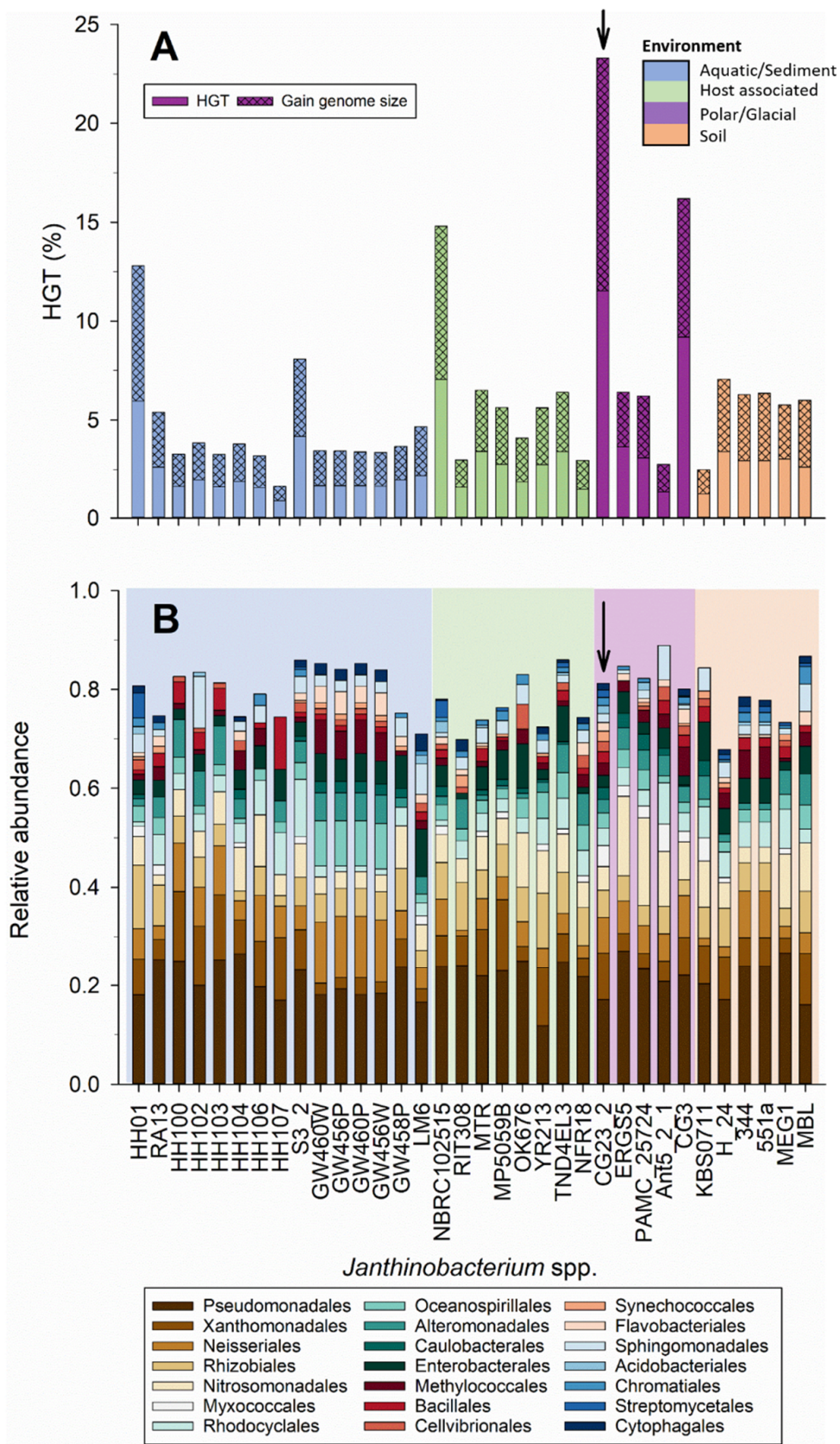

Figure 7. (A) Percentage of putatively horizontally transferred genes identified for the 34 Janthinobacterium spp. (B) Relative abundance of predicted horizontal gene transfer (HGT) donors based on the 20 most abundant orders identified in Janthinobacterium sp. CG23_2. Data are presented at the order level. Shaded colors indicate the five environments. Arrows mark Janthinobacterium sp. CG23_2. 
Table 2. Function and clusters of orthologous groups (COG) category for abundant putatively identified HGT events in Janthinobacterium sp. CG23_2. (For COG ID description see Table S4).

\begin{tabular}{|c|c|}
\hline Function & COG ID and (\#) of Protein Coding Sequences \\
\hline \multicolumn{2}{|l|}{ TRANSPORT } \\
\hline $\mathrm{ABC}$ transporters $(n=5)$ & $\begin{array}{l}\text { ABC-type amino acid transport/signal transduction systems, periplasmic } \\
\text { component/domain: COG0834 (5) }\end{array}$ \\
\hline Outer membrane proteins $(n=4)$ & Choline dehydrogenase and related flavoproteins: COG2303 (4) \\
\hline \multicolumn{2}{|r|}{ ENVIRONMENTAL SENSING } \\
\hline \multirow{2}{*}{ Signaling $(n=11)$} & Signal transduction histidine kinase: COG0642 (6) \\
\hline & c-di-GMP synthetase (diguanylate cyclase, GGDEF domain): COG2199 (5) \\
\hline Response regulator $(n=3)$ & $\begin{array}{l}\text { Response regulator containing a CheY-like receiver domain and an HTH } \\
\text { DNA-binding domain: COG2197 (3) }\end{array}$ \\
\hline \multirow{3}{*}{ DEFENSE $(n=27)$} & RTX toxins and related $\mathrm{Ca}^{2+}$-binding proteins: COG2931 (7) \\
\hline & Rhs family protein: COG3209 (13) \\
\hline & Beta-lactamase class C and other penicillin-binding proteins: COG1680 (4) \\
\hline MOBILOME $(n=24)$ & $\begin{array}{c}\text { Phage proteins: COG3497 (3), COG3772 (2), COG4626 (2), COG4695 (2), } \\
\text { COG3500 (1), COG3561 (1), COG3628 (1), COG3645 (1), COG3646 (1), } \\
\text { COG3740 (1), COG3948 (1), COG4653 (1), COG5362 (1) } \\
\text { Transposase: COG2963 (2), COG3666 (1), COG3335 (1), COG3415 (1), } \\
\text { COG2801 (1) }\end{array}$ \\
\hline DNA/RNA/REPAIR $(n=27)$ & $\begin{array}{l}\text { Superfamily I DNA and RNA helicases: COG0210 (3) } \\
\text { Transcriptional regulators: COG1309 (5), COG0583 (5), COG1846 (2), } \\
\text { COG1609 (1) } \\
\text { AraC-type DNA-binding domain-containing proteins: COG2207 (5) }\end{array}$ \\
\hline \multicolumn{2}{|l|}{ METABOLISM } \\
\hline Fermentation $(n=8)$ & $\begin{array}{c}\text { Dehydrogenases with different specificities (related to short-chain alcohol } \\
\text { dehydrogenases): COG1028 (6) } \\
\text { Short-chain alcohol dehydrogenase of unknown specificity: COG4221 (2) } \\
\text { Mannose-6-phosphate isomerase: COG0662 (4) }\end{array}$ \\
\hline \multicolumn{2}{|l|}{ BIOSYNTHESIS } \\
\hline Peptidoglycan $(n=5)$ & Glycosyltransferase: COG0438 (5) \\
\hline \multirow[t]{2}{*}{ Fatty acids $(n=4)$} & 3-oxoacyl-(acyl-carrier-protein) synthase: COG0304 (4) \\
\hline & Pentapeptide repeats containing protein: COG1357 (6) \\
\hline \multirow[t]{2}{*}{ Proteins $(n=12)$} & Acetyltransferases: COG0456 (3) \\
\hline & Acetyltransferases, including $n$-acetylases of ribosomal proteins: COG1670 (3) \\
\hline
\end{tabular}

\section{Discussion}

Unlike core genomes, which may consist of conserved genes essential to the lifestyle of specific taxonomic groups, the accessory genome is more likely subject to genome evolution and provides selective advantages under specific environmental conditions [45]. Only $18.7 \%$ of all CDSs identified in the Janthinobacterium sp. CG23_2 genome matched protein sequences to one or more of the other 35 Janthinobacterium spp. genomes. Further, with merely 164 CDSs being identified in both the Janthinobacterium sp. CG23_2 genome and the core gene set of 30 Janthinobacterium spp., these results reinforce the importance of a species-specific accessory genome and the genomic variability of Janthinobacterium sp. CG23_2. While it should be noted that gene duplication was not determined, putatively identified HGT events alone increase the genome size of Janthinobacterium sp. CG23_2 by $0.92 \mathrm{Mb}$. HGT events were mainly associated with signal transduction histidine kinases, second messengers, response regulators, and functions linked to defense/stress mechanisms (Table 2). These are all advantageous traits for survival and adaptation to extreme environments (discussed below). HGT is made possible primarily by the mobilome, including transposons and bacteriophages. Notable was the occurrence of 27 COGs denoting transposases in the species-specific accessory genome of Janthinobacterium sp. CG23_2, enzymes which catalyze the rearrangement or transfer of mobile genetic elements (i.e., transposons) within or between cells [46]. In a meta-analysis of 384 bacterial genomes, Newton and Bordenstein [47] determined that up to $\sim 6 \%$ of bacterial genomes could be the result of bacteriophage genes. These authors also established a correlation between larger genome sizes and an 
increase in the number of bacteriophage genes. While the Janthinobacterium sp. CG23_2 genome is by far the largest genome of the 36 Janthinobacterium species investigated, bacteriophage genes account for only $0.6 \%$ of its gene content. Smith et al. [48] reported virus to bacterium ratios ranging from 0.12 to 0.44 for the Cotton Glacier stream, 10-1000 fold lower compared to other polar inland waters [49]. Such low viral abundance in the Cotton Glacier stream may have limited the integration of phage genes into the bacterial chromosome of Janthinobacterium sp. CG23_2.

The species-specific accessory genome of Janthinobacterium sp. CG23_2 is dominated by functions associated with environmental signaling and transcriptional regulation (Figure 4). While both functions are predominant in the core genome of the genus Janthinobacterium [22], their enrichment in the species-specific accessory genome of Janthinobacterium sp. CG23_2 underscores their role in the adaptation to life in an ephemeral supraglacial Antarctic stream. Moreover, the importance of environmental sensing and orchestrating gene expression were firmly established in the cold-adaptation patterns of protein coding sequences (Table S3). Of relevance were gene categories related to signal transduction histidine kinases and response regulators containing CheY-like receivers. Histidine kinases and response regulators are the building blocks of the two-component signal transduction system, enabling an adaptive response to environmental stimuli (e.g., changes in $\mathrm{pH}$ and osmolarity levels, thermal and oxidative stress, light, nutrients and metal ions, and antimicrobials), mainly through gene expression [50]. Moreover, histidine kinases play a central role in the signal integration of the bacterial chemotaxis pathway, where auto-phosphorylated substrates transfer the phosphoryl group to CheY (CheY-P) [51]. Subsequently, the diffusible response regulator CheY-P interacts with the flagellar motor and reverses the rotation of flagella [51]. In line with these findings, the species-specific accessory genome of Janthinobacterium sp. CG23_2 possesses chemotaxis genes for sensing environmental cues and the movement towards factors that favor survival. Methyl-accepting chemotaxis proteins were the predominant chemoreceptors: proteins involved in biofilm formation and exopolysaccharide production, flagellum biosynthesis, degradation of xenobiotic compounds, and the production of toxins [52]. In addition to chemotaxis proteins, the presence of c-di-GMP phosphodiesterases and c-di-GMP synthetases suggests the possibility of reciprocal interactions between different chemosensory systems. c-di-GMP, a second messenger, inhibits the methyltransferase activity of methyl-accepting chemotaxis proteins. Ultimately, this modulation affects the phosphorylation of the CheY-like proteins and chemotactic responses [53]. As such, the c-di-GMP signaling system regulates the transition between motile-sessile states [54], lifestyle switches that enhance adaptation to fluctuations in the environment [55]. The species-specific accessory genome of Janthinobacterium sp. CG23_2 is equipped with gene categories associated with flagellar biosynthesis, basal body, hook, and motor proteins $(n=80)$ as well as pilus assembly proteins $(n=32)$. While the latter aids the adhesion of a bacterial cell to surfaces, flagella permit chemotaxis-navigated motility systems that allow for active locomotion. Temperature, osmolarity, $\mathrm{pH}$, and nutrient concentration can trigger the expression of the flagellar master operon, which facilitates switching between a motile and sessile state [56]. With their involvement in detecting wetness [57], flagella participate collectively in the sensing of environmental conditions crucial for successful propagation in a supraglacial stream.

The genome composition of Janthinobacterium sp. CG23_2 revealed temperature and oxidative stress as major environmental challenges associated with a supraglacial stream environment. Overall, 1760 and 577 protein coding sequences in the Janthinobacterium sp. CG23_2 genome were predicted to be cold-adapted when compared to the Janthinobacterium species isolated from mesophilic and polar/glacial habitats, respectively. Both the increased levels of UV radiation above the Antarctic Ice Sheet and low temperatures can lead to the formation of reactive oxygen species, posing a lethal threat to bacterial cells. Protection against oxidative damage in the genome of Janthinobacterium sp. CG23_2 included genes such as catalases, hydroperoxide reductases, peroxiredoxins, cytochrome c peroxidases, glutathione peroxidases, glutaredoxins, and thioredoxin reductases, many of which were cold-adapted (Table S3). The species-specific accessory genome of Janthinobacterium sp. CG23_2 also contains 15 copies of cold-adapted glutathione S-transferases. Not only do bacterial glutathione 
transferases provide protection against oxidative stresses, they also play a key role in cellular detoxification including processes such as the biodegradation of xenobiotics and antimicrobial drug resistance [58]. Further, choline dehydrogenases $(n=7)$ were found in the species-specific accessory genome of Janthinobacterium sp., and oxidize the first of the two enzymatic steps in the production of glycine-betaine [59]. This compatible solute is a known cryoprotectant and osmolyte and is believed to prevent cold-induced aggregation of proteins and maintain membrane fluidity $[59,60]$. In addition to genes coping with environmental stresses, Rhs protein families $(n=35)$ are included in the species-specific accessory genome of Janthinobacterium sp. CG23_2. Rhs proteins are part of a contact-dependent growth inhibition system. Intercellular competition is mediated by injecting toxins that inhibit the growth of neighboring cells [61], thereby providing a competitive advantage in a low-nutrient environment such as the Cotton Glacier stream [29].

For bacteria to sense and adapt to their ever-changing environment, modifications in signaling and gene regulation pathways are essential [62]. By implication, genotypic selection would depend on the complexity of the environment. Clearly, the temporal heterogeneity of the supraglacial Cotton Glacier stream, Antarctica, poses challenges for its microbial inhabitants within the time frame of both a single and multiple generations. A major survival advantage in this fluctuating environment would be the ability to anticipate changes in the environment [63,64]. Investigations by Mitchell et al. [65], for instance, showed that by using heat shock as the early stimulus, certain bacterial or yeast cells gained protection against stresses to come (e.g., oxidative stress, oxygen depletion). Similarly, a specific response to one stress could increase the resistance to another [66]. While experimental evidence for anticipating stressors or the physiological cross-protection to secondary stresses were beyond the scope of the present study, the genome of Janthinobacterium sp. CG23_2 is well equipped with ample genes associated with environmental sensing related functions, transcription regulators, and stress response.

In the context of the Black Queen Hypothesis, cells can evolve in two ways, by either losing gene functions and mutually depending on other members of a community or by retaining large genomes expressing many genes that are not essential to central metabolism, growth, and reproduction [30]. Although the latter would seem energetically unfavorable in an extreme environment such as the Cotton Glacier stream, Janthinobacterium sp. CG23_2 has evolved through genome plasticity (i.e., horizontal gene transfer and transposase activity), features that have been suggested to enable adaptation to life in cold environments $[67,68]$. The question of whether this gene acquisition represents a common trend in the adaptation to the Cotton Glacier stream environment or Janthinobacterium sp. CG23_2 acquired a key status as a function-performing helper within the microbial community according to the Black Queen Hypothesis invites further studies on the network of interactions between co-occurring organisms and their genome evolution. Both whole genome in silico DDH $(21.5 \pm 1.8 \%)$ and ANI $(79.3 \pm 0.4 \%)$ qualified well below the cut-off value for species boundaries [69]. These results were in accordance with the distant branching of Janthinobacterium sp. CG23_2 within the Maximum Likelihood tree (Figure 1). Based on these molecular and phylogenetic indicators, Janthinobacterium sp. CG23_2 appears sufficiently different to constitute a separate species. The new species Janthinobacterium cottonii is proposed. Additional taxonomic studies will help in placing Janthinobacterium cottonii within the genus Janthinobacterium.

In conclusion, comparative sequence analysis of 36 Janthinobacterium spp. genomes revealed a high degree of speciation of Janthinobacterium sp. CG23_2. Initially it was hypothesized that ecological niche specialization would result in genome streamlining; however, the genome of Janthinobacterium sp. CG23_2 is significantly larger than other Janthinobacterium spp. and has distinct accessory genome features (i.e., environmental sensing, locomotion, response and transcriptional regulation, stress response, and mobile elements) which are well adapted to and suited for proliferation in the ephemeral and extreme conditions of the Antarctic stream. The results highlight how the genome plasticity of closely-related organisms can support the adaptation of individual species to specific environmental niches. 
Supplementary Materials: The following are available online at http://www.mdpi.com/2076-2607/7/10/454/s1. Supplemental Figure S1: 16S rRNA gene tree. Supplemental Table S1: Pairwise comparisons of coding sequences (CDSs) identified in 36 Janthinobacterium spp. Genomes. Supplemental Table S2: Results for sequences of in silico DNA-DNA hybridization (DDH) and average nucleotide identity (ANI). Supplemental Table S3: Function and COG category for cold-adapted protein-coding sequences in Janthinobacterium sp. CG23_2. Supplemental Table S4: List of clusters of orthologous groups (COGs).

Author Contributions: H.J.S. and C.M.F. conceived the study. M.D., H.J.S., T.R., and C.M.F. developed the analytical frame work. M.D. and T.R. analyzed the data. M.D., H.J.S., T.R., and C.M.F. wrote the paper.

Acknowledgments: We thank R. Mueller at Montana State University for guidance on bioinformatics analyses. This work was supported by the National Science Foundation under grant ANT-0838970 to CMF. Any opinions, findings, and conclusions or recommendations expressed in this material are those of the authors and do not necessarily reflect the views of the National Science Foundation.

Conflicts of Interest: The authors declare no conflict of interest.

\section{References}

1. Benn, D.; Evans, D.J. Glaciers and Glaciation; Arnold: London, UK, 1998.

2. Goordial, J.; Lamarche-Gagnon, G.; Lay, C.Y.; Whyte, L. Left out in the cold: Life in cryoenvironments. In Polyextremophiles, Life under Multiple Forms of Stress; Seckbach, J., Oren, A., Stan-Lotter, H., Eds.; Springer: Dordrecht, The Netherlands, 2013; Volume 27, pp. 335-363.

3. Pfeffer, W.T.; Arendt, A.A.; Bliss, A.; Bolch, T.; Cogley, J.G.; Gardner, A.S.; Hagen, J.O.; Hock, R.; Kaser, G.; Kienholz, C.; et al. The Randolph Consortium. The Randolph Glacier Inventory: A globally complete inventory of glaciers. J. Glaciol. 2014, 60, 537-552. [CrossRef]

4. De Maayer, P.; Anderson, D.; Cary, C.; Cowan, D.A. Some like it cold: Understanding the survival strategies of psychrophiles. EMBO Rep. 2014, 15, 508-517. [CrossRef] [PubMed]

5. Casanueva, A.; Tuffin, M.; Cary, C.; Cowan, D.A. Molecular adaptations to psychrophily: The impact of 'omic'technologies. Trends Microbiol. 2010, 18, 374-381. [CrossRef] [PubMed]

6. Goordial, J.; Raymond-Bouchard, I.; Zolotarov, Y.; de Bethencourt, L.; Ronholm, J.; Shapiro, N.; Woyke, T.; Stromvik, M.; Greer, C.W.; Bakermans, C.; et al. Cold adaptive traits revealed by comparative genomic analysis of the eurypsychrophile Rhodococcus sp. JG3 isolated from high elevation McMurdo Dry Valley permafrost, Antarctica. FEMS Microbiol. Ecol. 2016, 92, 154.

7. Bowman, J.P. Genomics of psychrophilic bacteria. In Psychrophiles: From Biodiversity to Biotechnology; Margesin, R., Ed.; Springer: Cham, Switzerland, 2017; pp. 345-387.

8. Kawamoto, J.; Kurihara, T.; Esaki, N. Proteomic insights of psychrophiles. In Psychrophiles: From Biodiversity to Biotechnology; Margesin, R., Ed.; Springer: Cham, Switzerland, 2017; pp. 423-435.

9. Mann, S.; Chen, Y.P. Bacterial genomic G + C composition-eliciting environmental adaptation. Genomics 2010, 95, 7-15. [CrossRef] [PubMed]

10. Math, R.K.; Jin, H.M.; Kim, J.M.; Hahn, Y.; Park, W.; Madsen, E.L.; Jeon, C.O. Comparative genomics reveals adaptation by Alteromonas sp. SN2 to marine tidal-flat conditions: Cold tolerance and aromatic hydrocarbon metabolism. PLoS ONE 2012, 7, e35784. [CrossRef]

11. Feng, S.; Powell, S.M.; Wilson, R.; Bowman, J.P. Extensive gene acquisition in the extremely psychrophilic bacterial species Psychroflexus torquis and the link to sea-ice ecosystem specialism. Genome Biol. Evol. 2014, 6, 133-148. [CrossRef]

12. Dsouza, M.; Taylor, M.W.; Turner, S.J.; Aislabie, J. Genome-based comparative analyses of Antarctic and temperate species of Paenibacillus. PLoS ONE 2014, 9, e108009. [CrossRef]

13. Smith, H.J.; Foreman, C.M.; Akiyama, T.; Franklin, M.J.; Devitt, N.P.; Ramaraj, T. Genome sequence of Janthinobacterium sp. CG23_2, a violacein-producing isolate from an Antarctic supraglacial stream. Genome Announc. 2016, 4, e01468. [CrossRef]

14. Schloss, P.D.; Allen, H.K.; Klimowicz, A.K.; Mlot, C.; Gross, J.A.; Savengsuksa, S.; McEllin, J.; Clardy, J.; Ruess, R.W.; Handelsman, J. Psychrotrophic strain of Janthinobacterium lividum from a cold Alaskan soil produces prodigiosin. DNA Cell Biol. 2010, 29, 533-541. [CrossRef]

15. Kim, S.J.; Shin, S.C.; Hong, S.G.; Lee, Y.M.; Lee, H.; Lee, J.; Choi, I.G.; Park, H. Genome sequence of Janthinobacterium sp. strain PAMC 25724, isolated from alpine glacier cryoconite. J. Bacteriol. 2012, 194, 2096. [CrossRef] [PubMed] 
16. Avguštin, J.A.; Bertok, D.Ž.; Kostanjšek, R.; Avguštin, G. Isolation and characterization of a novel violacein-like pigment producing psychrotrophic bacterial species Janthinobacterium svalbardensis sp. nov. Anton Leeuw Int. J. G 2013, 103, 763-769. [CrossRef] [PubMed]

17. Smith, H.; Akiyama, T.; Foreman, C.; Franklin, M.; Woyke, T.; Teshima, H.; Davenport, K.; Daligault, H.; Erkkila, T.; Goodwin, L.; et al. Draft genome sequence and description of Janthinobacterium sp. strain CG3, a psychrotolerant Antarctic supraglacial stream bacterium. Genome Announc. 2013, 1, e00960. [CrossRef] [PubMed]

18. Koo, H.; Strope, B.M.; Kim, E.H.; Shabani, A.M.; Kumar, R.; Crowley, M.R.; Andersen, D.T.; Bej, A.K. Draft genome sequence of Janthinobacterium sp. Ant5-2-1, isolated from proglacial Lake Podprudnoye in the Schirmacher Oasis of East Antarctica. Genome Announc. 2016, 4, e01600. [CrossRef]

19. Gong, X.; Skrivergaard, S.; Korsgaard, B.S.; Schreiber, L.; Marshall, I.P.; Finster, K.; Schramm, A. High quality draft genome sequence of Janthinobacterium psychrotolerans sp. nov., isolated from a frozen freshwater pond. Stand. Genom. Sci. 2017, 12, 8. [CrossRef]

20. Rafiq, M.; Hayat, M.; Anesio, A.M.; Jamil, S.U.; Hassan, N.; Shah, A.A.; Hasan, F. Recovery of metallo-tolerant and antibiotic resistant psychrophilic bacteria from Siachen glacier, Pakistan. PLoS ONE 2017, 12, e0178180. [CrossRef]

21. Chiriac, C.; Baricz, A.; Coman, C. Draft genome sequence of Janthinobacterium sp. strain ROICE36, a putative secondary metabolite-synthesizing bacterium isolated from Antarctic snow. Genome Announc. 2018, 6, e01553. [CrossRef]

22. Kumar, R.; Acharya, V.; Singh, D.; Kumar, S. Strategies for high-altitude adaptation revealed from high-quality draft genome of non-violacein producing Janthinobacterium lividum ERGS5: 01. Stand. Genom. Sci. 2018, 13, 11. [CrossRef]

23. Brucker, R.M.; Harris, R.N.; Schwantes, C.R.; Gallaher, T.N.; Flaherty, D.C.; Lam, B.A.; Minbiole, K.P. Amphibian chemical defense: Antifungal metabolites of the microsymbiont Janthinobacterium lividum on the salamander Plethodon cinereus. J. Chem. Ecol. 2008, 34, 1422-1429. [CrossRef]

24. Lincoln, S.P.; Fermor, T.R.; Tindall, B.J. Janthinobacterium agaricidamnosum sp. nov., a soft rot pathogen of Agaricus bisporus. Int. J. Syst. Evol. Microbiol. 1999, 49, 1577-1589. [CrossRef]

25. Rossolini, G.M.; Condemi, M.A.; Pantanella, F.; Docquier, J.D.; Amicosante, G.; Thaller, M.C. Metallo- $\beta$-lactamase producers in environmental microbiota: New molecular class B enzyme in Janthinobacterium lividum. Antimicrob. Agents Chemother. 2001, 45, 837-844. [CrossRef] [PubMed]

26. Hornung, C.; Poehlein, A.; Haack, F.S.; Schmidt, M.; Dierking, K.; Pohlen, A.; Schulenburg, H.; Blokesch, M.; Plener, L.; Jung, K.; et al. The Janthinobacterium sp. HH01 genome encodes a homologue of the V. cholerae CqsA and L. pneumophila LqsA autoinducer synthases. PLoS ONE 2013, 8, e55045. [CrossRef] [PubMed]

27. Gillis, M.; De Ley, J. The genera Chromobacterium and Janthinobacterium. In The Prokaryotes A Handbook on the Biology of Bacteria, 3rd ed.; Dworkin, M., Falkow, S., Rosenberg, E., Schleifer, K.-H., Stackebrandt, E., Eds.; Springer: New York, NY, USA, 2006; pp. 737-746.

28. SanClements, M.D.; Smith, H.J.; Foreman, C.M.; Tedesco, M.; Chin, Y.P.; Jaros, C.; McKnight, D.M. Biogeophysical properties of an expansive Antarctic supraglacial stream. Antarct. Sci. 2017, 29, $33-44$. [CrossRef]

29. Foreman, C.M.; Cory, R.M.; Morris, C.E.; SanClements, M.D.; Smith, H.J.; Lisle, J.T.; Miller, P.L.; Chin, Y.P.; McKnight, D.M. Microbial growth under humic-free conditions in a supraglacial stream system on the Cotton Glacier, Antarctica. Environ. Res. Lett. 2013, 8, 035022. [CrossRef]

30. Morris, J.J.; Lenski, R.E.; Zinser, E.R. The Black Queen Hypothesis: Evolution of dependencies through adaptive gene loss. MBio 2012, 3, e00036-12. [CrossRef]

31. Giovannoni, S.J.; Thrash, J.C.; Temperton, B. Implications of streamlining theory for microbial ecology. ISME J. 2014, 8, 1553. [CrossRef]

32. Cleary, A.; Ramaraj, T.; Kahanda, I.; Mudge, J.; Mumey, B. Exploring frequented regions in pan-genomic graphs. IEEE ACM Trans. Comput. Biol. Bioinform. 2018. [CrossRef]

33. Wu, T.D.; Watanabe, C.K. GMAP: A genomic mapping and alignment program for mRNA and EST sequences. Bioinformatics 2005, 21, 1859-1875. [CrossRef]

34. Parks, D.H.; Imelfort, M.; Skennerton, C.T.; Hugenholtz, P.; Tyson, G.W. CheckM: Assessing the quality of microbial genomes recovered from isolates, single cells, and metagenomes. Genome Res. 2015, 25, 1043-1055. [CrossRef] 
35. Matsen, F.A.; Kodner, R.B.; Armbrust, E.V. pplacer: Linear time maximum-likelihood and Bayesian phylogenetic placement of sequences onto a fixed reference tree. BMC Bioinform. 2010, 11, 538. [CrossRef]

36. Kumar, S.; Stecher, G.; Tamura, K. MEGA7: Molecular evolutionary genetics analysis version 7.0 for bigger datasets. Mol. Biol. Evol. 2016, 33, 1870-1874. [CrossRef] [PubMed]

37. Letunic, I.; Bork, P. Interactive tree of life (iTOL) v3: An online tool for the display and annotation of phylogenetic and other trees. Nucleic Acids Res. 2016, 44, W242-W245. [CrossRef] [PubMed]

38. Meier-Kolthoff, J.P.; Auch, A.F.; Klenk, H.P.; Göker, M. Genome sequence-based species delimitation with confidence intervals and improved distance functions. BMC Bioinform. 2013, 14, 60. [CrossRef] [PubMed]

39. Goris, J.; Konstantinidis, K.T.; Klappenbach, J.A.; Coenye, T.; Vandamme, P.; Tiedje, J.M. DNA-DNA hybridization values and their relationship to whole-genome sequence similarities. Int. J. Syst. Evol. Microbiol. 2007, 57, 81-91. [CrossRef] [PubMed]

40. Rodriguez-R, L.M.; Konstantinidis, K.T. The enveomics collection: A toolbox for specialized analyses of microbial genomes and metagenomes. PeerJ. Preprints 2016, 4, e1900v1.

41. Altschul, S.F.; Madden, T.L.; Schäffer, A.A.; Zhang, J.; Zhang, Z.; Miller, W.; Lipman, D.J. Gapped BLAST and PSI-BLAST: A new generation of protein database search programs. Nucleic Acids Res. 1997, 25, 3389-3402. [CrossRef] [PubMed]

42. Wu, S.; Zhu, Z.; Fu, L.; Niu, B.; Li, W. WebMGA: A customizable web server for fast metagenomic sequence analysis. BMC Genom. 2011, 12, 444. [CrossRef]

43. Galperin, M.Y.; Makarova, K.S.; Wolf, Y.I.; Koonin, E.V. Expanded microbial genome coverage and improved protein family annotation in the COG database. Nucleic Acids Res. 2015, 43, D261-D269. [CrossRef]

44. Zhu, Q.; Kosoy, M.; Dittmar, K. HGTector: An automated method facilitating genome-wide discovery of putative horizontal gene transfers. BMC Genom. 2014, 15, 717. [CrossRef]

45. González-Torres, P.; Rodríguez-Mateos, F.; Antón, J.; Gabaldón, T. Impact of homologous recombination on the evolution of prokaryotic core genomes. MBio 2019, 10, e2494-18. [CrossRef]

46. Frost, L.S.; Leplae, R.; Summers, A.O.; Toussaint, A. Mobile genetic elements: The agents of open source evolution. Nat. Rev. Microbiol. 2005, 3, 722. [CrossRef] [PubMed]

47. Newton, I.L.; Bordenstein, S.R. Correlations between bacterial ecology and mobile DNA. Curr. Microbiol. 2011, 62, 198-208. [CrossRef] [PubMed]

48. Smith, H.J.; Foster, R.A.; McKnight, D.M.; Lisle, J.T.; Littmann, S.; Kuypers, M.M.; Foreman, C.M. Microbial formation of labile organic carbon in Antarctic glacial environments. Nat. Geosci. 2017, 10, 356-359. [CrossRef]

49. Säwström, C.; Lisle, J.; Anesio, A.M.; Priscu, J.C.; Laybourn-Parry, J. Bacteriophage in polar inland waters. Extremophiles 2008, 12, 167-175. [CrossRef] [PubMed]

50. Bhate, M.P.; Molnar, K.S.; Goulian, M.; DeGrado, W.F. Signal transduction in histidine kinases: Insights from new structures. Structure 2015, 23, 981-994. [CrossRef] [PubMed]

51. Sarkar, M.K.; Paul, K.; Blair, D. Chemotaxis signaling protein CheY binds to the rotor protein FliN to control the direction of flagellar rotation in Escherichia coli. Proc. Natl. Acad. Sci. USA 2010, 107, 9370-9375. [CrossRef]

52. Ud-Din, A.I.M.S.; Roujeinikova, A. Methyl-accepting chemotaxis proteins: A core sensing element in prokaryotes and archaea. Cell Mol. Life Sci. 2017, 74, 3293-3303. [CrossRef]

53. Xu, L.; Xin, L.; Zeng, Y.; Yam, J.K.; Ding, Y.; Venkataramani, P.; Cheang, Q.W.; Yang, X.; Tang, X.; Zhang, L.H.; et al. A cyclic di-GMP-binding adaptor protein interacts with a chemotaxis methyltransferase to control flagellar motor switching. Sci. Signal. 2016, 9, ra102. [CrossRef]

54. Pesavento, C.; Hengge, R. Bacterial nucleotide-based second messengers. Curr. Opin. Microbiol. 2009, 12, 170-176. [CrossRef]

55. Rossi, E.; Paroni, M.; Landini, P. Biofilm and motility in response to environmental and host-related signals in Gram negative opportunistic pathogens. J. Appl. Microbiol. 2018, 125, 1587-1602. [CrossRef]

56. Prüß, B.M.; Besemann, C.; Denton, A.; Wolfe, A.J. A complex transcription network controls the early stages of biofilm development by Escherichia coli. J. Bacteriol. 2006, 188, 3731-9373. [CrossRef] [PubMed]

57. Wang, Q.; Suzuki, A.; Mariconda, S.; Porwollik, S.; Harshey, R.M. Sensing wetness: A new role for the bacterial flagellum. EMBO J. 2005, 24, 2034-2042. [CrossRef] [PubMed]

58. Allocati, N.; Federici, L.; Masulli, M.; Di Ilio, C. Glutathione transferases in bacteria. FEBS J. 2009, 276, 58-75. [CrossRef] [PubMed] 
59. Sleator, R.D.; Hill, C. Bacterial osmoadaptation: The role of osmolytes in bacterial stress and virulence. FEMS Microbiol. Rev. 2002, 26, 49-71. [CrossRef] [PubMed]

60. Doyle, S.; Dieser, M.; Broemsen, E.; Christner, B. General characteristics of cold-adapted microorganisms. In Polar Microbiology: Life in a Deep Freeze; Miller, R.V., Whyte, L., Eds.; ASM Press: Wahington, DC, USA, 2012; pp. 103-125.

61. Jamet, A.; Nassif, X. New players in the toxin field: Polymorphic toxin systems in bacteria. MBio 2015, 6, e00285-15. [CrossRef] [PubMed]

62. Tetsch, L.; Jung, K. The regulatory interplay between membrane-integrated sensors and transport proteins in bacteria. Mol. Microbiol. 2009, 73, 982-991. [CrossRef]

63. Bleuven, C.; Landry, C.R. Molecular and cellular bases of adaptation to a changing environment in microorganisms. Proc. R. Soc. B-Biol. Sci. 2016, 283, 20161458. [CrossRef]

64. Pinto, D.; Mascher, T. (Actino) bacterial "intelligence": Using comparative genomics to unravel the information processing capacities of microbes. Curr. Genet. 2016, 62, 487-498. [CrossRef]

65. Mitchell, A.; Romano, G.H.; Groisman, B.; Yona, A.; Dekel, E.; Kupiec, M.; Dahan, O.; Pilpel, Y. Adaptive prediction of environmental changes by microorganisms. Nature 2009, 460, 220-224. [CrossRef]

66. Wang, G.; Doyle, M.P. Heat shock response enhances acid tolerance of Escherichia coli O157: H7. Lett. Appl. Microbiol. 1998, 26, 31-34. [CrossRef]

67. Allen, M.A.; Lauro, F.M.; Williams, T.J.; Burg, D.; Siddiqui, K.S.; De Francisci, D.; Chong, K.W.; Pilak, O.; Chew, H.H.; De Maere, M.Z.; et al. The genome sequence of the psychrophilic archaeon, Methanococcoides burtonii: The role of genome evolution in cold adaptation. ISME J. 2009, 3, 1012. [CrossRef] [PubMed]

68. Shen, L.; Yao, T.; Liu, Y.; Jiao, N.; Kang, S.; Xu, B.; Zhang, S.; Liu, X. Downward-shifting temperature range for the growth of snow-bacteria on glaciers of the Tibetan Plateau. Geomicrobiol. J. 2014, 31, 779-787. [CrossRef]

69. Richter, M.; Rosselló-Móra, R. Shifting the genomic gold standard for the prokaryotic species definition. Proc. Natl. Acad. Sci. USA 2009, 106, 19126-19131. [CrossRef] [PubMed]

(C) 2019 by the authors. Licensee MDPI, Basel, Switzerland. This article is an open access article distributed under the terms and conditions of the Creative Commons Attribution (CC BY) license (http://creativecommons.org/licenses/by/4.0/). 